\title{
Prevalence of molecular markers associated with drug resistance of Plasmodium vivax isolates in Western Yunnan Province, China
}

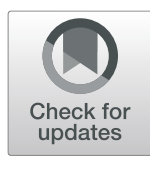

Xiaoxiao Wang ${ }^{1,2+}$, Wei Ruan ${ }^{2 \dagger}$, Shuisen Zhou $^{1 *}$, Xinyu Feng ${ }^{1}$, He Yan ${ }^{1}$ and Fang Huang ${ }^{1 *}$

\begin{abstract}
Background: Plasmodium vivax is the most widely distributed malaria parasite, and its drug resistance poses unique challenges to malaria elimination. The Greater Mekong Subregion (GMS) is known as the global epicenter of multidrug resistance. Surveillance of molecular markers associated with drug resistance in this area will help to inform drug policy.

Methods: Dry blood spots from 58 patients out of 109 with P. vivax infection between 2017, December and 2019, March were obtained from Yingjiang County, Yunnan Province, along the China-Myanmar border. Pvdhfr, Pvdhps, Pvmdr1 and Pvcrt-o were amplified and sequenced to assess gene mutations. The polymorphism and prevalence of these molecular markers were analyzed.

Results: Mutations in Pvdhfr at codons 57, 58, 61, 99 and 117 were detected in 27.59, 48.28, 27.59, 32.76 and $48.28 \%$ of the isolates, respectively. Single mutant haplotype $\left({ }_{13} \mathrm{~F}_{57} \mathrm{~S}_{58} \mathrm{~T}_{61} \mathrm{~S}_{99} \mathrm{~S}_{117} \mathrm{I}_{173}\right)$ was the most frequent (29.31\%, 17/58), followed by double mutant haplotype $(20.69 \%, 12 / 58)$. Of three types of tandem repeat variations of Pvdhfr, deletion type was the most common. Pvdhps showed a lower prevalence among mutation genotypes. Single mutant was dominant and accounted for 34.48\% (20/58). Prevalence of Pvmdr1 mutations at codons 958 and 1076 were $100.00 \%$ and $84.48 \%$, respectively. The proportion of double and single mutant types was $84.48 \%(49 / 58)$ and $15.52 \%$ (9/58), respectively. Eleven samples $(18.97 \%, 11 / 58)$ showed K10 "AAG" insertion in chloroquine resistance transporter gene Pvcrt-o.

Conclusions: There was moderate diversity of molecular patterns of resistance markers of Pvdhfr, Pvdhps, Pvmdr1 and Pvcrt-o in imported P. vivax cases to Yingjiang county in Western Yunnan, along the China-Myanmar border. Prevalence and molecular pattern of candidate drug resistance markers Pvdhfr, Pvdhps, Pvmdr1 and Pvcrt-o were demonstrated in this current study, which would help to update drug policy.
\end{abstract}

\section{Background}

Plasmodium vivax is the most widely distributed malaria parasite, and although it causes less significant morbidity and mortality than Plasmodium falciparum does, it

\footnotetext{
*Correspondence: zhouss@nipd.chinacdc.cn; huangfang@nipd.chinacdc.cn

${ }^{\dagger}$ Xiaoxiao Wang and Wei Ruan contributed equally to this work.

${ }^{1}$ National Institute of Parasitic Diseases, Chinese Center for Disease Control and Prevention, Key Laboratory of Parasite and Vector Biology, $\mathrm{MOH}$, and WHO Collaborating Centre for Malaria, Schistosomiasis and Filariasis, Shanghai, People's Republic of China

Full list of author information is available at the end of the article
}

poses unique challenges in many countries [1]. In 2017, it was estimated to be responsible for 7.5 million cases globally, and nearly 56\% in Southeast Asia [2]. Recently, there has been a massive reduction in malaria cases and deaths in the Greater Mekong Subregion (GMS), which comprises Cambodia, Yunnan Province of China, Lao People's Democratic Republic, Myanmar, Thailand and Vietnam. However, GMS has been the global epicenter of multidrug resistance. Resistance emerged to chloroquine (CQ) in the 1960s, sulfadoxine-pyrimethamine 
(SP) in the 1970s, mefloquine in the late 1990s, and artemisinin in 2008, and then spread progressively throughout other malaria-endemic areas [3-6]. This has raised concern from the World Health Organization (WHO) and local health authorities $[2,7,8]$. Malaria transmission in international border areas is usually confounded by population mobility and distinct chemotherapy policies and antimalarial strategies. The China-Myanmar border, as part of the GMS, included 18 counties of Yunnan Province. Although no indigenous cases have been identified in Yunnan Province since 2017, P. vivax remains a challenge, with increasing evidence of abundant vector species richness and diversity, high malaria vulnerability resulting from mobile population, as well as drug resistance $[9,10]$. In Myanmar, the proportion of malaria cases caused by $P$. vivax has increased steadily since 2012 [11].

CQ was first produced in 1934 and quickly proved to be one of the most successful and important antimalarial agents [12]. Nevertheless, the heavy use of CQ throughout subsequent decades eventually led to drug resistance. $P$. falciparum developed resistance in various areas since the 1950s, but drug-resistant $P$. vivax was not reported until the 1980s in Indonesia and Papua New Guinea [12, 13]. To date, CQ-resistant $P$. vivax has been confirmed in more than 10 countries, including Myanmar and China [14]. There has been a long history of successful application of SP in combating malaria due to its safety, good tolerance and long-lasting activity [15]. In China, as a component of the two combination regimens, pyrimethamine was widely used for malaria prophylaxis between the mid-1960s and early 1990s [16]. By now, SP is recommended by WHO as one of the partner drugs for treatment of $P$. falciparum in the GMS, as well as intermittent preventive treatment for infants, children and pregnant women $[2,15]$. Although $\mathrm{SP}$ is rarely used to treat $P$. vivax infection, the parasite is still under SP selection pressure, especially in endemic regions where co-infection with $P$. vivax and $P$. falciparum is common.

Compared with $P$. falciparum, it is more difficult to determine the underlying mechanisms of antimalarial drug resistance of $P$. vivax because there is no proper in vitro cultivation system for $P$. vivax. This means that the molecular mechanism of $P$. vivax resistance remains to be established. Several studies suggest that it involves multigenic loci, such as CQ resistance marker Pvcrt-o; multidrug resistance marker Pvmdr1; and antifolate resistance markers Pvdhps and Pvdhfr, which are conferred from homologous genes in P. falciparum [11, 17]. Data for molecular markers associated with drug resistance would be beneficial in addressing the resistant parasite. Few studies to date have defined the molecular epidemiology of $P$. vivax resistance markers on the China-Myanmar Border $[18,19]$. Here, we report the prevalence of molecular markers of drug resistance in $P$. vivax to facilitate appropriate drug policy in this region.

\section{Methods \\ Study site}

Yingjiang (Longitude 97 $31^{\prime} \sim 98^{\circ} 16^{\prime}$, Latitude 24 24' $\left.25^{\circ} 20^{\prime}\right)$ is one of the 18 counties along the ChinaMyanmar border, located west of Yunnan Province. It was selected as the study site due to its long borderline with Kachin State, Myanmar and being well documented as an epidemic area of resistant P. falciparum [18]. The land area of Yingjiang County is $4429 \mathrm{~km}^{2}$ and the local population was 316,990 by 2015 . It is located in the subtropical monsoon climate zones with an average annual temperature of $22.7^{\circ} \mathrm{C}$ and annual rainfall of 2.65 $\mathrm{m}$. Migration, plantation and logging activities are frequent at the border [18]. Anopheles minimus is reported to be the dominant species of mosquito [20]. Ninetythree malaria cases were reported in Yingjiang County in 2016 and 2017, respectively, and there were 103 cases in 2018. P. vivax was the dominant parasite and all the cases of malaria were imported after May, 2016.

\section{Sample collection and DNA extraction}

Isolates were obtained from 58 out of 109 confirmed $P$. vivax infected patients from December 2017 to March 2019 in Yingiiang County. All the infections were diagnosed and reported by hospitals or clinics in Yingjiang County. Yingiiang County Center for Disease Control and Prevention carried out epidemiological investigation of each patient. They were double-checked for species by PCR in Yunnan Institute of Parasitic Diseases. All the patients, according to epidemiological history, were imported from Laiza, Myanmar, which was along the China-Myanmar border. Thick and thin blood smears coupled with standard microscopy techniques were used to identify parasite species, then PCR was used to double check and confirm species. Approximately $200 \mu \mathrm{L}$ of finger-prick blood was obtained from each patient before treatment and spotted on Whatman $3 \mathrm{MM}$ filter paper $(10 \mathrm{~cm} \times 7 \mathrm{~cm}$, Cat. No. $3030-866)$ and air dried. The dried blood spot was about $6 \mathrm{~mm}$ for diameter. They were stored in small plastic zip lock bags with desiccants at $-20{ }^{\circ} \mathrm{C}$ before parasite genomic DNA extraction. QIAamp DNA Mini kit (Qiagen Inc., Hilden, Germany) was used to extract genomic DNA following the dried blood spot protocol.

\section{DNA amplification and sequencing}

Multiple molecular markers, Pvcrt-o, Pvmdr1, Pvdhps and $P v d h f r$, suspected conferring drug resistance on $P$. vivax, were detected. Pvcrt-o was amplified by regular PCR and Pvmdr1, Pvdhps and Pvdhfr by nested PCR, as previously described, with some modification $[17,21]$. 
Oligonucleotide primers and cycling conditions are listed in additional file (see Additional file: Table S1). A final $25-\mu \mathrm{L}$ reaction volume was performed, of which $1 \mu \mathrm{L}$ template genomic DNA was used in primary amplification reactions, and $1 \mu \mathrm{L}$ primary reaction products in the second round of amplification in the case of nested PCRs. Amplification products were sequenced by Sangon Biotech Co. Ltd. (Shanghai, China).

\section{Data analysis}

Nucleotide and amino acid sequences of Pvcrt-o, Pvmdr1, $P v d h p s$ and $P v d h f r$ were aligned and compared with reference sequences from NCBI database by Mega version 7.0.26 (https://www.megasoftware.net/). Accession numbers for reference sequences were: Pvcrt-o (AF314649), Pvmdr1(AY618622), Pvdhps (XM001617159) and Pvdhfr(X98123). A database was constructed by Microsoft Excel 2017, and descriptive statistical analysis was performed with SPSS Statistics for Windows version 21.0 (IBM Corp., Armonk, NY, USA). Categorial data were summarized by percentage, quantitative variables were expressed as median.

\section{Results}

\section{General information}

We collected data from 58 patients (40 males,68.97\%; 28 females,31.03\%) with $P$. vivax infections between 2017

Table 1 General information of $P$. vivax infections

\begin{tabular}{ll}
\hline General information & Number (\%) \\
\hline Year & $3(5.17)$ \\
2017 & $52(89.66)$ \\
2018 & $3(5.17)$ \\
Gender & \\
Male & $40(68.97)$ \\
Female & $18(31.03)$ \\
Age & \\
Range & $3 \sim 69 \mathrm{yr}$ \\
Median & $34.5 \mathrm{yr}$ \\
History of malaria infection & \\
Yes & $9(15.52)$ \\
No & $49(84.48)$ \\
Activities in Myanmar & \\
Planting & $29(50.00)$ \\
Visiting relatives or friends & $16(27.59)$ \\
Business trip & $4(6.90)$ \\
Trading & $4(6.90)$ \\
Living & $4(6.90)$ \\
\hline
\end{tabular}

and 2019, of which, the majority $(89.66 \%, 52 / 58)$ were collected in 2018. The median (range) age of the $58 \mathrm{pa}-$ tients was 34.5 (3-69) years. Nine $(15.52 \%)$ patients had a history of malaria. Most patients lived (4/58,6.90\%), studied $(1.72 \%, 1 / 58)$ or worked (planting,50.00\%,29/58; trading, 6.90\%,4/58) in Myanmar, whereas 20 patients were infected when they visited relatives or friends $(27.59 \%, 16 / 58)$, or during business trips $(6.90 \%, 4 / 58)$ in Myanmar (Table 1).

\section{Prevalence and patterns of Pvdhfr mutations}

Mutations in Pvdhfr at codons 57, 58, 61, 99 and 117 were detected in $27.59,48.28,27.59,32.76$ and $48.28 \%$ of isolates, respectively. No mutations were found at position 13 or 173 (Table 2). Analysis of Pvdhfr haplotype revealed that prevalence of mutant types was present at high levels (Table 3, Fig. 1). Both single and multiple mutant Pvdhfr (double, quadruple and quintuple) were found. Single mutant haplotype $\left(\mathrm{I}_{13} \mathrm{~F}_{57} \mathrm{~S}_{58} \mathrm{~T}_{61} \mathrm{~S}_{99} \mathrm{~S}_{117} \mathrm{I}_{173}\right)$ was the most frequent $(29.31 \%, 17 / 58)$, followed by double mutant haplotype $(20.69 \%, 12 / 58)$. Quadruple mutant haplotypes, exhibiting two distinct patterns, were also found in 14 isolates, and the pattern $\mathrm{I}_{13} I_{57} \mathbf{R}_{58} \mathbf{M}_{61} \mathrm{H}_{99} \mathbf{T}_{117} \mathrm{I}_{173}$ was more

Table 2 Prevalence of point mutations at specific positions in Pvcrt-o, Pvmdr1, Pvdhps and Pvdhfr of P. vivax isolates

\begin{tabular}{|c|c|c|}
\hline Genes & Mutation at codon & Number (\%) \\
\hline \multicolumn{3}{|l|}{ Pvdhfr } \\
\hline & 13 & 0 \\
\hline & 57 & $16(27.59)$ \\
\hline & 58 & $28(48.28)$ \\
\hline & 61 & $16(27.59)$ \\
\hline & $99^{*}$ & 19 (32.76) \\
\hline & 117 & $28(48.28)$ \\
\hline & 173 & 0 \\
\hline \multicolumn{3}{|l|}{ Pvdhps } \\
\hline & 382 & $1(1.72)$ \\
\hline & 383 & $29(50.00)$ \\
\hline & 512 & $1(1.72)$ \\
\hline & 553 & $9(15.52)$ \\
\hline & 580 & 0 \\
\hline & 585 & 0 \\
\hline \multicolumn{3}{|l|}{ Pvmdr1 } \\
\hline & 958 & $58(100.00)$ \\
\hline & 976 & 0 \\
\hline & 997 & 0 \\
\hline & 1076 & 49 (84.48) \\
\hline \multicolumn{3}{|l|}{ Pvert-o } \\
\hline & K10 insertion & $11(18.97)$ \\
\hline
\end{tabular}


Table 3 Prevalence of haplotypes of Pvcrt-o, Pvmdr1, Pvdhps and Pvdhfr in P. vivax isolates

\begin{tabular}{|c|c|c|c|}
\hline Genes & Haplotype & Codon $^{a}$ & Number (\%) \\
\hline \multicolumn{4}{|l|}{ Pvdhfr } \\
\hline & Wild type & $\mathrm{I}_{13} \mathrm{~F}_{57} \mathrm{~S}_{58} \mathrm{~T}_{61} \mathrm{H}_{99} \mathrm{~S}_{117} \mathrm{I}_{173}$ & $3(5.17)$ \\
\hline & Mutant type & & $55(94.83)$ \\
\hline & Mutant tandem repeat & $\mathrm{I}_{13} \mathrm{~F}_{57} \mathrm{~S}_{58} \mathrm{~T}_{61}-\mathrm{S}_{117} \mathrm{I}_{173}$ & $10(17.24)$ \\
\hline & Single mutant & $\mathrm{I}_{13} \mathrm{~F}_{57} \mathrm{~S}_{58} \mathrm{~T}_{61} \underline{\boldsymbol{S}}_{99} \mathrm{~S}_{117} \mathrm{I}_{173}$ & $17(29.31)$ \\
\hline & Double mutant and tandem repeat & $\mathrm{I}_{13} \mathrm{~F}_{57} \mathbf{R}_{58} \mathrm{~T}_{61}-\mathbf{N}_{117} \mathrm{I}_{173}$ & $12(20.69)$ \\
\hline & Quadruple mutant(a) & $\left.\mathrm{I}_{13} \mathbf{I}_{57} \mathbf{R}_{58} \mathbf{M}_{61} \mathrm{H}_{99} \mathbf{T}_{117}\right|_{173}$ & $9(15.52)$ \\
\hline & Quadruple mutant(b) & $\mathrm{I}_{13} \mathbf{L}_{57} \mathbf{R}_{58} \mathbf{M}_{61} \mathrm{H}_{99} \mathbf{T}_{117} \mathrm{I}_{173}$ & $5(8.62)$ \\
\hline & Quintuple mutant & $\left.\left.\right|_{13} \mathbf{I}_{57} \mathbf{R}_{58} \mathbf{M}_{61} \mathbf{S}_{99} \mathbf{T}_{117}\right|_{173}$ & $2(3.45)$ \\
\hline \multicolumn{4}{|l|}{ Pvdhps } \\
\hline & Wild type & $\mathrm{S}_{382} \mathrm{~A}_{383} \mathrm{~K}_{512} \mathrm{~A}_{553} \mathrm{R}_{580} \mathrm{~V}_{585}$ & $29(50.00)$ \\
\hline & Single mutant & $\mathrm{S}_{382} \mathbf{G}_{383} \mathrm{~K}_{512} \mathrm{~A}_{553} \mathrm{R}_{580} \mathrm{~V}_{585}$ & $20(34.48)$ \\
\hline & Double mutant & $\mathrm{S}_{382} \mathbf{G}_{383} \mathrm{~K}_{512} \mathbf{G}_{553} \mathrm{R}_{580} \mathrm{~V}_{585}$ & $8(13.79)$ \\
\hline & Quadruple mutant & $\mathbf{C}_{382} \mathbf{G}_{383} \mathbf{E}_{512} \mathbf{G}_{553} \mathrm{R}_{580} \mathrm{~V}_{585}$ & $1(1.72)$ \\
\hline \multicolumn{4}{|c|}{ Pvmdr1 } \\
\hline & Wild type & $\mathrm{T}_{958} \mathrm{Y}_{976} \mathrm{~K}_{997} \mathrm{~F}_{1076}$ & 0 \\
\hline & Single mutant & $\mathbf{M}_{958} \mathrm{Y}_{976} \mathrm{~K}_{997} \mathrm{~F}_{1076}$ & $9(15.52)$ \\
\hline & Double mutant & $\mathbf{M}_{958} \mathbf{Y}_{976} \mathbf{K}_{997} \mathbf{L}_{1076}$ & $49(84.48)$ \\
\hline \multicolumn{4}{|l|}{ Pvert-o } \\
\hline & Wild type & & $47(81.03)$ \\
\hline & Mutant ("AAG" insertion) & & $11(18.97)$ \\
\hline
\end{tabular}

a:Mutant amino acids are shown in bold

common. Quintuple mutant $\mathrm{I}_{13} \mathbf{I}_{57} \mathbf{R}_{58} \mathbf{M}_{61} \mathbf{S}_{99} \mathbf{T}_{117} \mathrm{I}_{173}$ was detected in two isolates. Notably, two genotypes were detected at codons 57 and 117. Specifically, F57I and F57L at position 57, were observed in $11(18.97 \%)$ and $5(8.62 \%)$ isolates, respectively, and the frequency for S117T and $\mathrm{S} 117 \mathrm{~N}$ was $16(27.59 \%)$ and $12(20.69 \%)$, respectively.

Three types of tandem repeat variations were found in $P v d h f r$. Type I was the same as the reference strain (accession number X98123), whereas type II showed mutant allele H99S, and type III exhibited a deletion of 18 nucleotides (ACACACGGTGGTGACAAC, translated into THGGDN) between amino acid positions 98 and 103 (Fig. 2). Type III was the most common, accounting for $37.93 \%$ (22/58), followed by Type II which was observed in $19(32.76 \%)$ isolates. In addition, more than half of Type III isolates $(12 / 22,54.55 \%)$ also carried S58R and S117N mutations.

\section{Prevalence and patterns of Pvdhps mutations}

All 58 samples were successfully amplified for Pvdhps. Compared with $P v d h f r, P v d h p s$ showed a relatively lower prevalence of mutation genotypes. Minority of isolates carried mutations at codons $382(1.72 \%, 1 / 58), 512$ $(1.72 \%, 1 / 58)$ and 553 (15.52\%, 9/58) (Fig. 2). Mutation at position 383 was detected in half of the isolates.
Among the mutant types, single mutant was dominant and accounted for $34.48 \%(20 / 58)$. Double mutant $\mathrm{S}_{382} \mathbf{G}_{383} \mathrm{~K}_{512} \mathbf{G}_{553} \mathrm{R}_{580} \mathrm{~V}_{585}$ was less frequent (13.79\%, 8/ 58). Quadruple mutant $\mathbf{C}_{382} \mathbf{G}_{383} \mathbf{E}_{512} \mathbf{G}_{553} R_{580} \mathrm{~V}_{585}$ was only found in one $P$. vivax isolate. S382C and K512E were rarely observed in previous studies.

Prevalence and patterns of Pvmdr1 and Pvcrt-o mutations Prevalence of mutations at codons Pvmdr1 958 and 1076 was 100.00 and $84.48 \%$, respectively. No single nucleotide polymorphism was present at either codon 976 or 997. Analysis of Pvmdr1 haplotype prevalence showed that all the isolates were mutant type. In particular, double mutant type predominated $(84.48 \%, 49 / 58)$. Single mutant was found in nine isolates $(15.52 \%, 9 / 58)$. Eleven samples $(18.97 \%, 11 / 58)$ showed K10 "AAG" insertion in CQ resistance transporter gene Pvcrt-o (Fig. 2). A combined analysis of all mutations in 58 samples revealed 25 different haplotypes (see Additional file: Table S2).

\section{Discussion}

Drug resistance is of great concern for malaria control and prevention, especially in GMS, necessitating monitoring resistance to antimalarial agents. However, since its first report in 1989, the burden of drug-resistant $P$. 


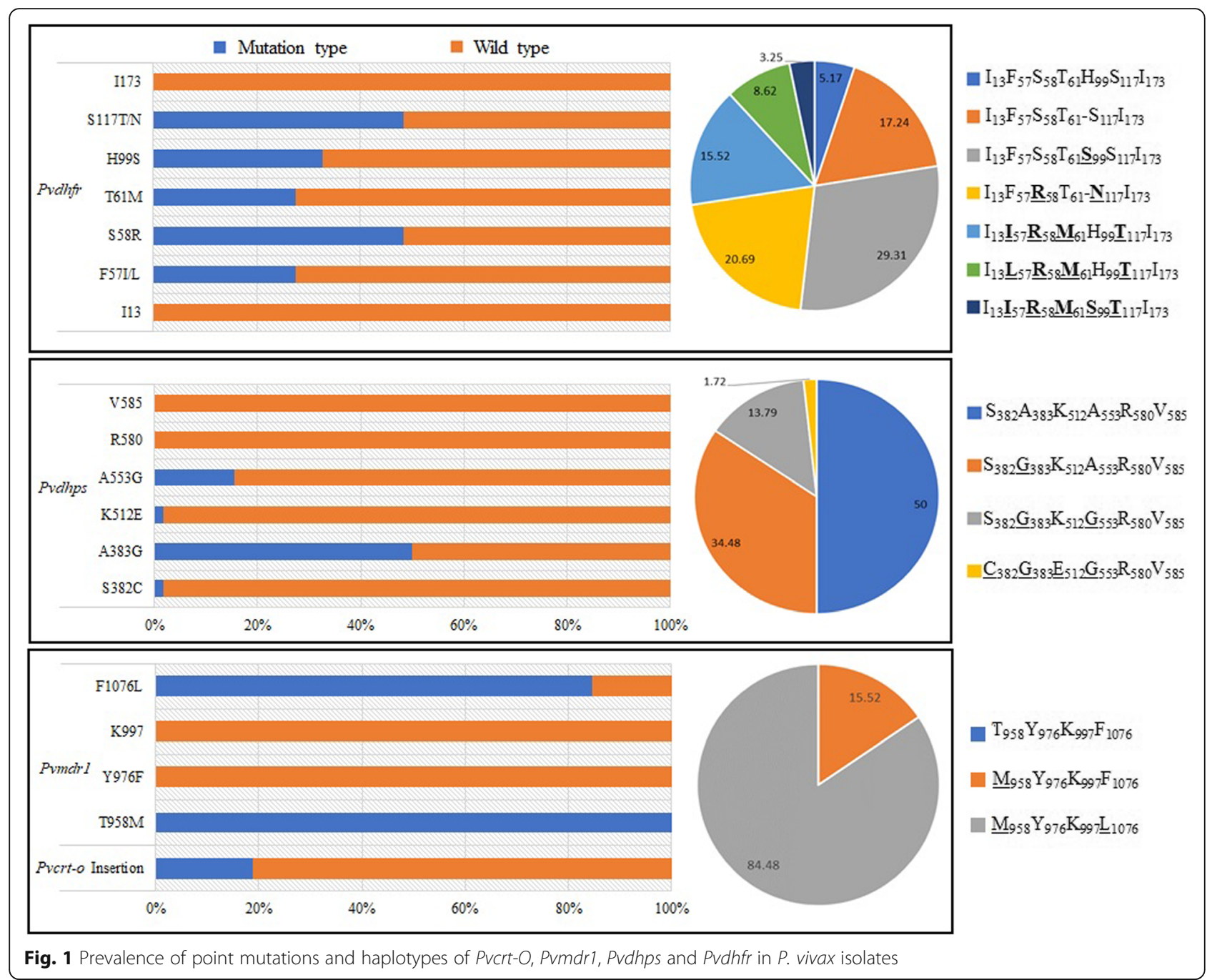

vivax is still unclear and its underlying mechanism, epidemiology and drug efficacy have not been well characterized [17]. Four main methods, in vivo therapeutic efficacy studies, in vitro assay, drug concentration measurement, as well as molecular markers analysis, are used to monitor antimalarial drug efficacy and resistance. Among these, molecular markers are widely preferred due to their practical advantages over in vivo and in vitro tests. Molecular markers allow population-level screening, and samples on filter paper are easily obtained, transported and stored, thus avoiding host confounding factors [22]. The epidemiology of drug resistance of $P$. vivax varies across the GMS, hence molecular marker surveillance is encouraged to inform local drug policy.

In the present study, the prevalence of Pvdhfr mutation type, including point mutation and mutant tandem repeat, was high $(94.83 \%, 55 / 58)$, which was similar to the reports in southern Thailand and western Myanmar. However, one study in Xishuangbanna Prefecture of Yunnan Province (southern Yunnan, bordering Myanmar in the west and Laos and Vietnam in the south) between 2009 and

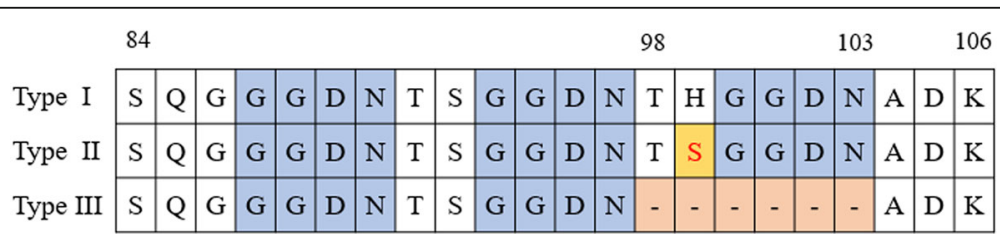

Fig. 2 Sequence alignment of tandem repeat region between amino acid positions 84 and 106 in Pvdhfr gene. Dashes represent tandem repeat deletion between 98 and 103. Blue indicates the tandem repeat. Orange denotes the mutant at codon 99 
2010, and another in India between 2005 and 2007, found that prevalence of $P v d h f r$ was lower than in our study [16] $[17,23,24]$. Furthermore, point mutations at codons 57, 58, 61 and 117 in the Pvdhfr gene were detected in 27.59$48.28 \%$ of isolates in the current study. These results were lower than those in southern Thailand and western Myanmar, but higher than those in Xishuangbanna of Yunnan and India $[16,17,23,24]$. Regarding the patterns of mutation types, single and double mutants were the dominant genotypes in western Yunnan in our study, while quadruple mutation was the most common in Myanmar, Thailand and southern Yunnan [16, 17, 23, 25]. Previous studies identified that mutations at residues 117 and 58 arose first under drug pressure, so they were more highly mutated than others [26]. These results confirmed that the mutation types at codons 117 and 58 were the most frequent. Triple and quadruple mutations were more associated with high level of SP resistance than double or single mutations were. Our study indicated that $P$. vivax in western Yunnan might be under stronger drug pressure than those in western Myanmar and southern Thailand [27].

Mutant tandem repeats are also suggested to be associated with $P$. vivax antifolate resistance, and the frequency of Type II (H99S type) and Type III (deletion type) was 32.75 and $37.93 \%$, respectively. This was consistent with a previous studies that reported that most isolates in India and Cambodia were deletion type [24, 28]. Nevertheless, the highest frequency of tandem repeat variants was for wild type in southern Thailand and Xishuangbanna Prefecture, Yunnan [16, 23]. In Anhui Province (Central China), Type II (H99S type) was the most common [16].

Similar to Pvdhfr, the frequency of mutant Pvdhps, especially the highly mutant types (triple or quadruple types), was less than that in southern Thailand and southern Myanmar [21, 23]. In addition, compared with another border region, Xishuangbannan of Yunnan, Pvdhps in our sampling region was more conserved, with higher proportions of wild type and fewer highly mutated types, although the isolates from Xishuangbannan were collected nearly 10 years ago [16]. Considering the similar drug policy in this study area and Xishuangbannan, it is still unclear whether the disagreement resulted from spatial heterogeneity or drug susceptibility to sulfadoxine.and as such, further study is required.

Several studies have provided evidence that Pvmdr1 mutations are associated with reduced susceptibility to CQ $[17,29,30]$. Therefore, Pvmdr1 is considered to be a strong candidate marker of drug resistance [23]. The prevalence of Pvmdr1 T958M and F1076L mutations in our study was consistent with previous studies, showing that T958F was harbored in all the isolates and F1076L was in most of them $[13,21]$. However, no Y976F was found in our study, while it was frequently reported with considerable prevalence in different endemic areas, including Indonesia, Thailand, Cambodia, India, Papua New Guinea and Ethiopia [29-35]. This is not surprising as $98.51 \%$ of patients were categorized as having an adequate clinical and parasitological response to CQ by an in vivo therapeutic efficacy study in Yingjiang and Tengchong, Yunnan [36]. Our study indicated that Pvmdr1 at codon 976 was conserved in this area, although this needs to be confirmed.

The possible role of Pvcrt-o in CQ resistance is controversial. Several studies have found a negative link between $\mathrm{K} 10$ insertion and reduced $\mathrm{CQ} \mathrm{IC}_{50}$, while others have shown that Pvcrt-o expression decreased susceptibility to CQ by 2.2-fold [30, 37]. The K10 Pvcrt-o gene insertion was found in $18.97 \%$ isolates in our study, which was less than in previous studies in Myanmar that reported 46.15\% in Yangon in 1999, 72.73\% in Shwegyin, $66.67 \%$ in Kawthaung and $48.33 \%$ in Buthidaung between 2009 and 2016 [17, 35]. Conversely, K10 insertion was rarely observed in Thailand from 2012 to 2018, or from the Thailand-Myanmar border or ThailandCambodia border in 2008 or 2014 [21, 23]. Given the geographical genetic differences among parasite populations from the GMS, the prevalence of K10 insertion in Pvcrt-o in the current and previous studies showed significant temporal and spatial heterogeneity [38]. The discrepancy may have resulted from differences in study sites or sample size.

\section{Conclusions}

In conclusion, the present study demonstrated the prevalence and molecular pattern of candidate drug resistance markers Pvdhfr, Pvdhps, Pvmdr1 and Pvcrt-o of imported $P$. vivax cases to Yingjiang county in Western Yunnan, along the China-Myanmar border. Diversity of molecular patterns of resistance markers Pvdhfr, Pvdhps, Pvmdr1 and Pvcrt-o was found. This study helped to provide evidence for drug policy update.

\section{Supplementary information}

Supplementary information accompanies this paper at https://doi.org/10. 1186/s12879-020-05032-4.

Additional file 1 Table S1 Primers and cycling conditions for Pvcrt-o, Pvmdr1, Pvdhps and Pvdhfr genotyping assay. Table S2 Combined analysis of all mutations from $P$. vivax isolates.

\section{Abbreviations}

GMS: Greater Mekong subregion; WHO: World Health Organization; $\mathrm{CQ}$ : Chloroquine; $\mathrm{IC}_{50}$ : Inhibitory concentration 50

\section{Acknowledgments}

We are grateful to the physicians and staff of the Yingjiang county Center for Disease Control and Prevention for their invaluable assistance in sample collection and epidemiological investigation. 


\section{Authors' contributions}

XXW, XYF and HY carried out the molecular studies. SSZ and FH conceived the study. XXW and WR analyzed the data and drafted the manuscript. All authors read and approved the final manuscript.

\section{Funding}

This work was funded by the National Important Scientific \& Technological Project (2018ZX10101002-002), National Health Commission Special Project for Lancang-Mekong Cooperation in 2017 (No.2020399), Natural Science Foundation of Shanghai (No. 18ZR1443400), and National Institutes of Health/National Institute of Allergy and Infectious Diseases U19 project (No. U19Al129386). The funders had no role in study design, data collection, data analysis and the preparation of the manuscript.

\section{Availability of data and materials}

The datasets analyzed in this study are available from the corresponding author on reasonable request.

\section{Ethics approval and consent to participate}

This study was approved by the Ethical Review Committee of National Institute of Parasitic Diseases, Chinese Center for Disease Control and Prevention (No. 20160818).

\section{Consent for publication}

Not applicable.

\section{Competing interests}

The authors declare that they have no competing interests.

\section{Author details}

'National Institute of Parasitic Diseases, Chinese Center for Disease Control and Prevention, Key Laboratory of Parasite and Vector Biology, $\mathrm{MOH}$, and WHO Collaborating Centre for Malaria, Schistosomiasis and Filariasis, Shanghai, People's Republic of China. ${ }^{2}$ Zhejiang Provincial Center for Disease Control and Prevention, Zhejiang, People's Republic of China.

\section{Received: 27 September 2019 Accepted: 15 April 2020}

\section{Published online: 25 April 2020}

\section{References}

1. WHO: Control and elimination of Plasmodium vivax malaria: a technical brief. 2015.

2. WHO. World Malaria Report. Geneva: WHO; 2019

3. Harinasuta T, Suntharasamai P, Viravan C. Chloroquine-resistant falciparum malaria in Thailand. Lancet. 1965:2(7414):657-60.

4. Harald N, Youry S, Kurt S, Smith BL, Duong S, Fukuda MM. Evidence of artemisinin-resistant malaria in western Cambodia. N Engl J Med. 2008; 359(24):2619-20

5. Dondorp AM, Nosten F, Yi P, Das D, Phyo AP, Tarning J, Lwin KM, Ariey F, Hanpithakpong W, Lee SJ, et al. Artemisinin resistance in Plasmodium falciparum malaria. N Engl J Med. 2009:361(5):455-67.

6. Cally R, Richard P, Shalini N, Brian S, Francois N, Tim A. Intercontinental spread of pyrimethamine-resistant malaria. Science (80- ). 2004;305(5687): 1124

7. WHO: Eliminating malaria in the Greater Mekong subregion united to end a deadly disease. 2016

8. Cotter C, Sturrock HJW, Hsiang MS, Liu J, Phillips AA, Hwang J, Gueye CS, Fullman N, Gosling RD, Feachem RGA. The changing epidemiology of malaria elimination: new strategies for new challenges. Lancet. 2013, 382(9895):900-11.

9. Zhang SS, Zhou SS, Zhou ZB, Chen TM, Wang XZ, Shi WQ, Jiang WK, Li JL, Zhou XN, Frutos $R$, et al. Monitoring of malaria vectors at the ChinaMyanmar border while approaching malaria elimination. Parasit Vectors. 2018;11(1):511.

10. Chen TM, Zhang SS, Feng J, Xia ZG, Luo CH, Zeng XC, Guo XR, Lin ZR, Zhou HN, Zhou SS. Mobile population dynamics and malaria vulnerability: a modelling study in the China-Myanmar border region of Yunnan Province. China. Infect Dis Poverty. 2018;7(1):36.

11. Htun MW, Mon NCN, Aye KM, Hlaing CM, Kyaw MP, Handayuni ! Trimarsanto $H$, Bustos D, Ringwald P, Price RN, et al. Chloroquine efficacy for
Plasmodium vivax in Myanmar in populations with high genetic diversity and moderate parasite gene flow. Parasites \& Vectors. 2017;16(1):281.

12. Wellems TE, Plowe CV. Chloroquine-resistant malaria. J Infect Dis. 2001; 184(6):770-6.

13. Barnadas C, Ratsimbasoa A, Tichit M, Bouchier C, Jahevitra M, Picot S, Menard D. Plasmodium vivax resistance to chloroquine in Madagascar: clinical efficacy and polymorphisms in pvmdr1 and pvcrt-o genes. Antimicrob Agents Chemother. 2008;52(12):4233-40.

14. Guthmann JP, Pittet A, Lesage A, Imwong M, Lindegardh N, Min Lwin M, Zaw T, Annerberg A, de Radigues X, Nosten F. Plasmodium vivax resistance to chloroquine in Dawei, southern Myanmar. Tropical Med Int Health. 2008; 13(1):91-8.

15. Muller IB, Hyde JE. Folate metabolism in human malaria parasites--75 years on. Mol Biochem Parasitol. 2013;188(1):63-77.

16. Huang B, Huang S, Su XZ, Tong X, Yan J, Li H, Lu F. Molecular surveillance of pvdhfr, pvdhps, and pvmdr-1 mutations in plasmodium vivax isolates from Yunnan and Anhui provinces of China. Malar J. 2014:13:346.

17. Nyunt MH, Han JH, Wang B, Aye KM, Aye KH, Lee SK, Htut Y, Kyaw MP, Han KT, Han ET. Clinical and molecular surveillance of drug resistant vivax malaria in Myanmar (2009-2016). Malar J. 2017;16(1):117.

18. Feng J, Zhou D, Lin Y, Xiao H, Yan H, Xia Z. Amplification of pfmdr1, pfert, pvmdr1, and K13 propeller polymorphisms associated with plasmodium falciparum and plasmodium vivax isolates from the China-Myanmar border. Antimicrob Agents Chemother. 2015;59(5):2554-9.

19. Deng S, Ruan Y, Bai Y, Hu Y, Deng Z, He Y, Ruan R, Wu Y, Yang Z, Cui L. Genetic diversity of the Pvk12 gene in plasmodium vivax from the ChinaMyanmar border area. Malar J. 2016;15(1):528.

20. Guo Y, Guiyun Y, Naixin Z, Daibin Z, Ying W, Zhengbo H, Zhentian Y, Wenbo F, Feilong Y, Bin C. The Anopheles community and the role of Anopheles minimus on malaria transmission on the China-Myanmar border. Parasit Vectors. 2013;6(1):264

21. Tantiamornkul K, Pumpaibool T, Piriyapongsa J, Culleton R, Lek-Uthai U. The prevalence of molecular markers of drug resistance in plasmodium vivax from the border regions of Thailand in 2008 and 2014. Int J Parasitol Drugs Drug Resist. 2018;8(2):229-37.

22. WHO: Global rpeort on antimalarial drug efficacy and drug resistance 20002010. 2010.

23. Noisang C, Prosser C, Meyer W, Chemoh W, Ellis J, Sawangjaroen N, Lee R. Molecular detection of drug resistant malaria in southern Thailand. Malar J. 2019;18(1):275.

24. Prajapati SK, Joshi H, Dev V, Dua VK. Molecular epidemiology of plasmodium vivax anti-folate resistance in India. Malar J. 2011;10(1):102.

25. Ding S, Ye R, Zhang D, Sun X, Zhou H, Mccutchan TF, Pan W. Anti-folate combination therapies and their effect on the development of drug resistance in Plasmodium vivax. Sci Rep. 2013:3(s 1-2):1008.

26. Mallika I, Sasithon P, Laurent R, Franck L, Jean-Paul C, Ubolsree L, Sornchai L, White NJ, Georges S. Novel point mutations in the dihydrofolate reductase gene of plasmodium vivax: evidence for sequential selection by drug pressure. Antimicrob Agents Chemother. 2003:47(5):1514.

27. Imwong M, Pukrittakayamee S, Looareesuwan S, Pasvol G, Poirreiz J, White $\mathrm{N}$, Snounou G. Association of genetic mutations in plasmodium vivax dhf with resistance to sulfadoxine-pyrimethamine: geographical and clinical correlates. Antimicrob Agents Chemother. 2001:45(11):3122-7.

28. De Pecoulas PE, Tahar RP, Thai KH, Basco LK. Genetic variation of the dihydrofolate reductase gene in plasmodium vivax in Snoul, northeastern Cambodia. Acta Trop. 2004;92(1):1-6.

29. Suwanarusk R, Chavchich M, Russell B, Jaidee A, Chalfein F, Barends M, Prasetyorini B, Kenangalem E, Piera KA, Lekuthai U. Amplification of pvmdr1 associated with multidrug-resistant plasmodium vivax. J Infect Dis. 2008;198(10):1558-64.

30. Suwanarusk R, Russell $B$, Chavchich $M$, Chalfein F, Kenangalem E, Kosaisavee $V$, Prasetyorini B, Piera KA, Barends M, Brockman A, et al. Chloroquine resistant plasmodium vivax: in vitro characterisation and association with molecular polymorphisms. PLoS One. 2007;2(10):e1089.

31. Brega $S$, Meslin B, de Monbrison F, Severini C, Gradoni L, Udomsangpetch $R$, Sutanto I, Peyron F, Picot S. Identification of the plasmodium vivax mdr-like gene (pvmdr1) and analysis of single-nucleotide polymorphisms among isolates from different areas of endemicity. J Infect Dis. 2005;191(2):272-7.

32. Chaorattanakawee S, Lon C, Chann S, Thay KH, Kong N, You Y, Sundrakes S, Thamnurak C, Chattrakarn S, Praditpol C, et al. Measuring ex vivo drug susceptibility in plasmodium vivax isolates from Cambodia. Malar J. 2017;16(1):392 
33. Schousboe ML, Ranjitkar S, Rajakaruna RS, Amerasinghe PH, Morales F, Pearce R, Ord R, Leslie T, Rowland M, Gadalla NB, et al. Multiple Origins of Mutations in the mdr1 Gene--A Putative Marker of Chloroquine Resistance in P. vivax. PLoS Negl Trop Dis. 2015;9(11):sS.

34. Golassa L, Erko B, Baliraine FN, Aseffa A, Swedberg G. Polymorphisms in chloroquine resistance-associated genes in plasmodium vivax in Ethiopia. Malar J. 2015;14:164

35. Lu F, Lim CS, Nam DH, Kim K, Lin K, Kim TS, Lee HW, Chen JH, Wang Y, Sattabongkot J, et al. Genetic polymorphism in pvmdr1 and pvcrt-o genes in relation to in vitro drug susceptibility of plasmodium vivax isolates from malaria-endemic countries. Acta Trop. 2011;117(2):69-75.

36. Liu H, Yang HL, Tang LH, Li XL, Huang F, Wang JZ, Li CF, Wang HY, Nie RH, Guo XR, et al. Monitoring plasmodium vivax chloroquine sensitivity along China-Myanmar border of Yunnan Province, China during 2008-2013. Malar J. 2014:13:364.

37. Sa JM, Yamamoto MM, Fernandez-Becerra C, de Azevedo MF, Papakrivos J, Naude B, Wellems TE, Del Portillo HA. Expression and function of pvcrt-o, a plasmodium vivax ortholog of pfert, in plasmodium falciparum and Dictyostelium discoideum. Mol Biochem Parasitol. 2006;150(2):219-28.

38. Zhu X, Zhao P, Wang S, Liu F, Liu J, Wang J, Yang Z, Yan G, Fan Q, Cao Y, et al. Analysis of Pvama1 genes from China-Myanmar border reveals little regional genetic differentiation of plasmodium vivax populations. Parasit Vectors. 2016;9(1):614.

\section{Publisher's Note}

Springer Nature remains neutral with regard to jurisdictional claims in published maps and institutional affiliations.

Ready to submit your research? Choose BMC and benefit from:

- fast, convenient online submission

- thorough peer review by experienced researchers in your field

- rapid publication on acceptance

- support for research data, including large and complex data types

- gold Open Access which fosters wider collaboration and increased citations

- maximum visibility for your research: over $100 \mathrm{M}$ website views per year

At $\mathrm{BMC}$, research is always in progress.

Learn more biomedcentral.com/submissions 